\title{
Hydraulic transients in pipelines due to various valve closure schemes
}

\author{
Mehmet Ishak Yuce ${ }^{1}$ (1) $\cdot$ Aram Faraidoon Omer ${ }^{1}$
}

(c) Springer Nature Switzerland AG 2019

\begin{abstract}
In this study, the hydraulic transient in a pipeline model was considered by utilizing the method of characteristics. The pipeline conveys water from the upstream reservoir to the downstream one, while a valve was set at the downstream end of it. The effect of sudden, linear and stepwise valve closure schemes were analysed by employing a stainless-steel pipe and a ductile pipe. Sudden valve closure was noted to generate higher-pressure transients than linear and stepwise schemes. As the closure time period increases, the value of the maximum pressure transient decreases, in both linear and stepwise arrangements. The transient pressure was perceived to be higher in stainless-steel pipe than in ductile one, in three closure schemes. The simulations were performed by a purpose-developed MATLAB code.
\end{abstract}

Keywords Hydraulic transients · Method of characteristics · Sudden valve closure - Linear valve closure · Stepwise valve closure · Pipeline

\section{Introduction}

A hydraulic transient, also known as water hammer or hydraulic shock, is a sharp pressure surge or a wave produced when water flow is forced to stop suddenly or change direction abruptly. Power failure of pumps, sudden valve actions and the operation of automatic control systems can cause a high pressure wave to propagate in pipeline systems, including domestic water-supply networks. If the necessary precautions are not taken, the transient conditions instigating high pressures can cause failures of pipes, valves and fittings and thus collapse of the pipeline systems. Hydraulic transients may adversely affect the quality of treated water. Surge tanks, expansion tanks, pressure safety valves or accumulators can be used to ease the impact of water hammer on pipelines and their fittings [1-9].

The experimental studies conducted by Weston [10], Carpenter [11] and Carpenter and Barraclough [12] are reported to be the first investigations on determining a correlation between the decrease in flow velocity in a pipe and the corresponding pressure surge. Frizell [13] studied water hammer in Ogden hydroelectric development with a $9.45 \mathrm{~km}$ long penstock. Joukowski $[14,15]$ has carried out extensive theoretical and experimental studies on the basic theory of water hammer. The pipelines which were used in the studies have the lengths of $7.62 \mathrm{~km}, 305 \mathrm{~m}$ and $305 \mathrm{~m}$ with diameters of $50 \mathrm{~mm}, 101.5 \mathrm{~mm}$ and $152.5 \mathrm{~mm}$, respectively. Joukowski derived a formula for the wave velocity, taking into consideration the elasticity of both water and the pipe walls. The general theory of water hammer was developed by Allievi [16], presenting an expression for the pressure rise at the valve and produced charts for pressure rise and fall caused by a uniform valve closure.

Since then, a number of studies have been published, refining the governing equations of water hammer [9, 17-21]. Their combined efforts have resulted in the classical mass and momentum equations for one-dimensional water hammer flow which is usually the basis for the numerical simulations. Karney and Ruus [22] and Elansary and Contractor [23] have investigated the influence of uniform, parabolic, equal percentage and optimum valve closure operation on hydraulic transients in pipelines. Sharp and Sharp [24] stated that two-stage valve closure

Mehmet Ishak Yuce, yuce@gantep.edu.tr | 1 Gaziantep University, Gaziantep, Turkey.

SN Applied Sciences (2019) 1:1110 | https://doi.org/10.1007/s42452-019-1146-4 
arrangement can be used to reduce transient pressure in pipes. Yu et al. [25] have advised to close a valve in two steps. The first segment of the pipe could be closed in a rapid manner, while the second segment should be closed in a slow way to avoid high transient pressures. Although water hammer effect has been studied since the beginning of the twentieth century [16], due to its complexity, several features of it still remain to be investigated. In this study, three different closure schemes of a butterfly valve and two diverse pipe types were considered in order to determine the best valve closure operation to minimize hydraulic transients in pipes.

Hydraulic transients in pipes have been analysed by a number of Eulerian- or Lagrangian-based methods. In this study, the method of characteristics (MOC) was utilized, which is one of the most widely used methods in simulation analyses and recognized to be producing accurate results. In MOC, the partial differential equations are reduced into a family of ordinary differential equations, along the characteristic line $[1,2,26,27]$. The conventional approach of the method is to define a fixed grid in the distance-time plane. On the grid, the unknown pressure and velocity values are numerically computed in a timearching procedure that begins from a given initial conditions. MOC predicts the maximum pressure in the system with a high precision. The maximum pressure generally occurs during the first surge. It also accurately forecasts the wave periods $[1,9,28]$.

\section{Governing equations}

The momentum and the continuity are the two essential equations utilized to calculate the hydraulic transient in pipes. They are nonlinear and first-order partial differential equations $[29,30]$.

Momentum : $g H_{x}+U U_{x}+U_{t}+\frac{f U|U|}{2 D}=0$

Continuity : $U H_{x}+H_{t}-U \sin \beta+\frac{C^{\prime 2}}{g} U_{x}=0$

where $H_{x}$ is the head at any distance from the upstream reservoir, $H_{\mathrm{t}}$ is the head at any time from the beginning of the flow, $U$ is the velocity of the flow, $U_{x}$ is the velocity at any distance from the upstream reservoir, $U_{t}$ is the velocity at any time from the beginning of the flow, $f$ is the pipe friction coefficient, $D$ is the pipe diameter, $\beta$ is the pipe slope, $C^{\prime}$ is the wave speed, and $g$ is the acceleration of gravity.

These two partial differential equations are transformed into two ordinary differential equations (Eqs. 3 and 5) by using the method of characteristics, with the condition that the respective equations (Eqs. 4 and 6) are valid [18, 19, 31].

$\left.\frac{g}{C^{\prime}} \frac{\mathrm{d} H}{\mathrm{~d} t}+\frac{E U}{\mathrm{~d} t}+\frac{f U|U|}{2 D}=0\right\} C^{+}$

$\left.\frac{\mathrm{d} x}{\mathrm{~d} t}=+C^{\prime}\right\} C^{+}$

$\left.-\frac{g}{C^{\prime}} \frac{\mathrm{d} H}{\mathrm{~d} t}+\frac{\mathrm{d} U}{\mathrm{~d} t}+\frac{f U|U|}{2 D}=0\right\} C^{-}$

$\left.\frac{\mathrm{d} x}{\mathrm{~d} t}=-C^{\prime}\right\} C^{-}$

where $H$ is the piezometric head, $x$ is the distance along the pipe, $D$ is the pipe diameter, $t$ is time, and $C^{\prime}$ is the celerity of a pressure wave in the pipeline. At the instant of the water hammer, a pressure wave propagates through the pipeline with a velocity which is function of pipe type and fluid properties $[1,19,32]$. The physical depiction of two pairs of equations on $x-t$ plane $\left(C^{-}\right.$and $\left.C^{+}\right)$is shown in Fig. 1. In this study, the hydraulic transient propagation wave speed was analysed for a stainless-steel pipe and a ductile pipe. The parameters utilized as input for the MAT$L A B$ code developed for this particular investigation are given in Table 1.

$C^{\prime}=\sqrt{\frac{\frac{E_{\mathrm{H}_{2} \mathrm{O}}}{\rho_{\mathrm{H}_{2} \mathrm{O}}}}{1+\frac{E_{\mathrm{H}_{2} \mathrm{O}} \mathrm{O}}{E_{\text {pipe }}} \cdot \frac{D}{e} \cdot C 1}}$

A pipeline is connected to two reservoirs with a certain head difference, and a butterfly valve is set at its

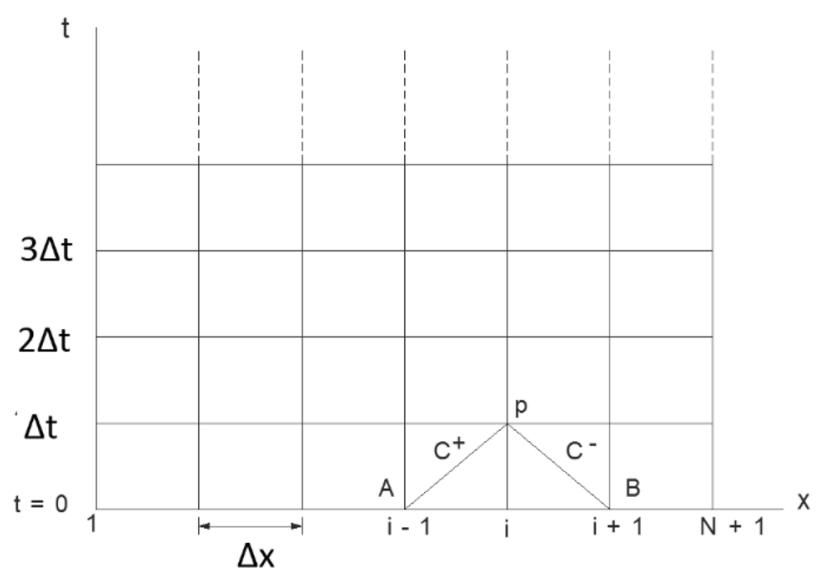

Fig. 1 Characteristic lines in the $x-t$ plane 
Table 1 Parameters used as input for the MATLAB code

\begin{tabular}{llll}
\hline Parameter & Symbol & Stainless-steel pipe & Ductile pipe \\
\hline Upstream reservoir head & $\mathrm{Hu}$ & $80 \mathrm{~m}$ & $80 \mathrm{~m}$ \\
Downstream reservoir head & $\mathrm{Hd}$ & $60 \mathrm{~m}$ & $60 \mathrm{~m}$ \\
Operating pressure head & $P$ & $60-80 \mathrm{~m}$ & $60-80 \mathrm{~m}$ \\
Maximum allowable pressure head & $P_{\max }$ & $300 \mathrm{~m}$ & $300 \mathrm{~m}$ \\
Pipe length & $L$ & $6000 \mathrm{~m}$ & $6000 \mathrm{~m}$ \\
Pipe diameter & $D$ & $0.40 \mathrm{~m}$ & $0.40 \mathrm{~m}$ \\
Thickness of pipe wall & $e$ & $4.1 \mathrm{~mm}$ & $8.1 \mathrm{~mm}$ \\
Pipe absolute roughness & $e^{*}$ & $45 \times 10^{-6} \mathrm{~m}$ & $2591 \times 10^{-6} \mathrm{~m}$ \\
Pipe loss coefficient & $f$ & 0.013 & 0.033 \\
Pipe bed slope & $\mathrm{S}$ & $0(\mathrm{level})$ & $0(\mathrm{level})$ \\
Gravity & $\mathrm{g}$ & $9.81 \mathrm{~m} / \mathrm{s}^{2}$ & $9.81 \mathrm{~m} / \mathrm{s}^{2}$ \\
Number of reaches on the pipe & $N$ & 6 & 6 \\
Modulus of elasticity of water & $E_{\mathrm{H}_{2} \mathrm{O}}$ & $2.1 \times 10^{9}$ & $2.1 \times 10^{9}$ \\
Modulus of elasticity of pipe material & $E_{\text {pipe }}$ & $210 \times 10^{9}$ & $167 \times 109$ \\
Density of water & $\rho$ & $1000 \mathrm{~kg} / \mathrm{m}^{3}$ & $1000 \mathrm{~kg} / \mathrm{m}^{3}$ \\
Viscosity of water & $\mu$ & $1.31 \times 10^{-6} \mathrm{~m}^{2} / \mathrm{s}$ & $1.31 \times 10^{-6} \mathrm{~m}^{2} / \mathrm{s}$ \\
Water temperature & Tmp. & $20{ }^{\circ} \mathrm{C}$ & $20{ }^{\circ} \mathrm{C}$ \\
C1-coefficient & $C 1$ & 1 & 1 \\
Wave speed & $\mathrm{C}^{\prime}$ & $1020 \mathrm{~m} / \mathrm{s}$ & $1140 \mathrm{~m} / \mathrm{s}$ \\
\hline
\end{tabular}

downstream end. The pipe is divided into $N$ segments of equal length $\Delta x$, while the time step is determined by the increment in $\Delta t$. The solution of the domain starts at the entrance of the pipeline, at $x_{1}=0$ and ends at $x_{n+1}=L$. Equations 3 and 4 should be satisfied and integrated along the $\mathrm{C}^{+}$line and written in terms of unknown variables of $U$ and $H$. If the dependent variables $U$ and $H$ are known at the upstream of a particular pipe segment, Eqs. 5 and 6 should be satisfied and integrated along the $C$ line. Simultaneous solution yields conditions at the particular time and the positions in the $x-t$ plane $[19,33,34]$.

\section{Valve closure schemes}

The butterfly valve set at the end of the pipe connecting the two reservoirs is closed abruptly in sudden closure scheme. While, in linear closure scheme, the valve was shut in one linear step, in stepwise closure scheme, the valve was closed in three unequal time intervals. In both the linear and the stepwise operations, six different closure time steps were considered. These time steps were $t=\lambda$, $2 \lambda, 5 \lambda, 10 \lambda, 20 \lambda$ and $50 \lambda$, where $\lambda=2 L / C^{\prime}$. The steps of the valve openings were fixed to be $100,40,30$ and 0 percent of the valve opening area in stepwise closure scheme. The
Fig. 2 Valve closure schemes. a Linear. b Stepwise
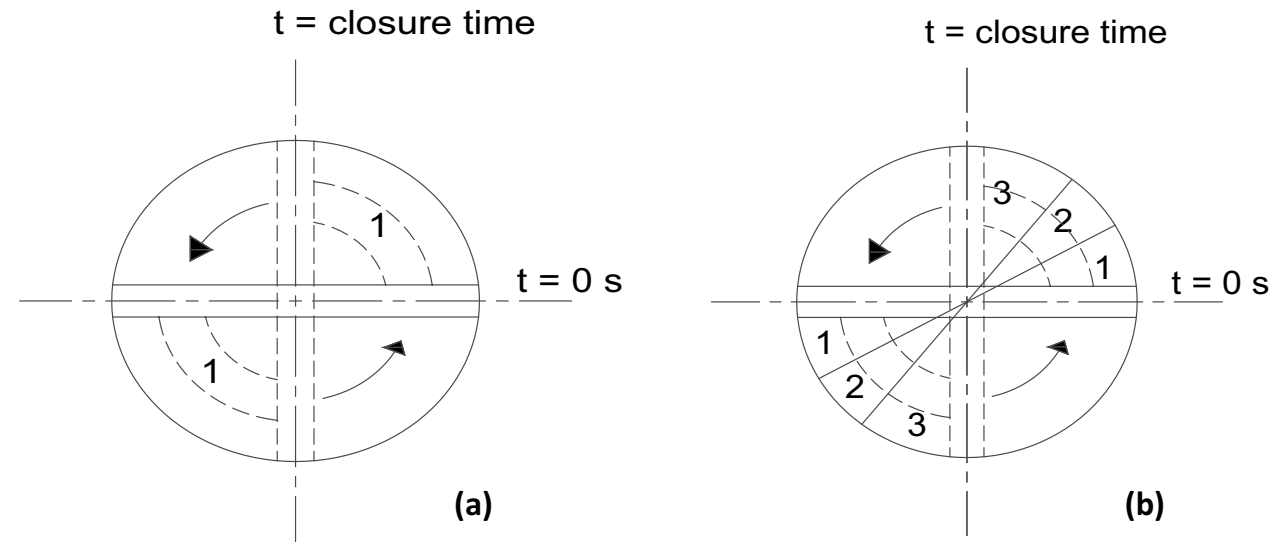
linear and stepwise valve closure operations are described in Fig. 2. The discharge coefficient of a valve is a function of the percentage of the valve opening area to its total area. The discharge coefficient of a classic butterfly valve is given in Tullis [35].

\section{Valve closure analysis}

In pipeline systems, valve closures cause pressure surge just at the upstream of the valve. This phenomenon instigates a pressure wave, which travels back through pipes, causing hydraulic transients or water hammer. The travel time for the pressure wave to reach to the upstream reservoir is " $L / C^{\prime \prime \prime}$ seconds after the closure of the valve. At this moment, the pressure at every point in the pipe (upstream of the valve) is equal to " $H+\Delta H$." This sudden increase in the head will continue until one round trip of the pressure wave. This travel time of the wave is $2 L / C^{\prime}=\lambda \mathrm{s}$. The pressure head reduces after the first round trip of the wave [32].

\subsection{Sudden valve closure}

As it is shown in Fig. 3, when the valve is suddenly closed, the pressure just at the upstream of the valve increases immediately. The value of the maximum transient pressure

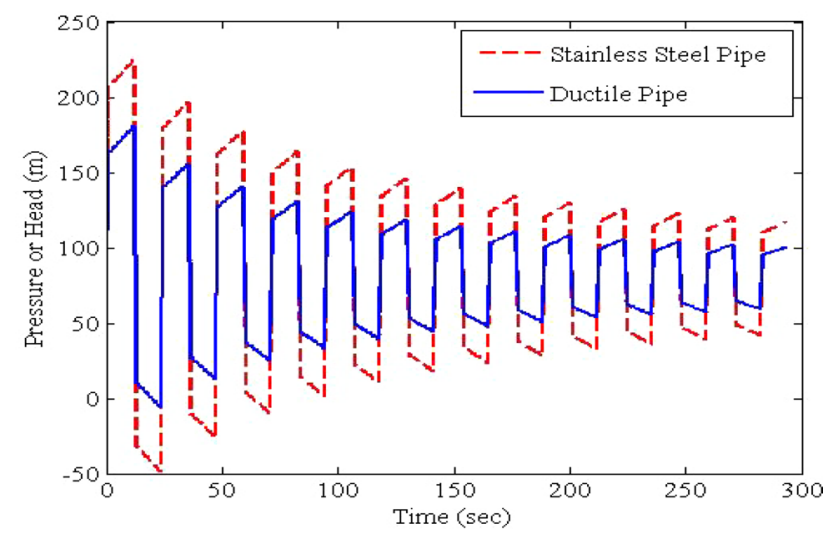

Fig. 3 Transient pressure fluctuation in sudden valve closure scheme in the pipeline is affected by several factors including the pipe material. In this investigation, two types of pipes were used, namely stainless steel and ductile. Under the same hydraulic conditions, the maximum transient pressure head observed in the stainless-steel pipe was $223.93 \mathrm{~m}$, while it was $180.03 \mathrm{~m}$ for the ductile pipe. Particularly, in sudden valve closure scheme, a ramp occurs at the top of the transient pressure fluctuation line. This ramp is called the line packing of the pipe, which is the frictional pressure drop with the length of the pipe. The slope of the ramp depends on the pressure head loss coefficient of the valve $[32,36]$.

\subsection{Linear valve closure}

Linear valve closure scheme was performed for six different closing time periods of $\lambda, 2 \lambda, 5 \lambda, 10 \lambda, 20 \lambda$ and $50 \lambda \mathrm{s}$, in ductile and stainless-steel pipes. Closure time periods are given in Table 2. Figure 4 illustrates the transient pressure fluctuations in the stainless-steel and ductile pipes just at the upstream of the valve. While, in stainless-steel pipe, the maximum and the minimum pressure heads were noted to be $217.62 \mathrm{~m}$ and $-43.64 \mathrm{~m}$ for closure time of $\lambda \mathrm{s}$, they were found to be $84.77 \mathrm{~m}$ and $60.05 \mathrm{~m}$ for $50 \lambda \mathrm{s}$. On the other hand, the maximum and the minimum pressure heads were found to be $174.61 \mathrm{~m}$ and $-1.70 \mathrm{~m}$ and $83.43 \mathrm{~m}$ and $60.02 \mathrm{~m}$ for closure time intervals of $\lambda$ and $50 \lambda \mathrm{s}$, respectively, in ductile pipe. The effect of the closure time on the magnitude of the transient pressures is detected in both pipes (Fig. 4). In both pipes, the maximum transient pressure values were witnessed to decrease with the increase in closure time period. Under the same hydraulic and valve closure conditions, the transient pressure generated in the ductile pipe was observed to be less than it was in stainless-steel pipe. There were no line packings perceived in the transient pressure curves with closure time period equal or larger than $t=2 \lambda$. However, for closure time period of $\lambda \mathrm{s}$, line packing was clearly noted.

\subsection{Stepwise valve closure}

Alike the linear closure scheme, six different closure time periods of $\lambda, 2 \lambda, 5 \lambda, 10 \lambda, 20 \lambda$ and $50 \lambda$ seconds were considered in the stepwise valve closure operation for both stainless-steel and ductile pipes. The percentages of
Table 2 Linear valve closure times

\begin{tabular}{lllllll}
\hline Pipes & \multicolumn{7}{l}{ Time $(\mathrm{s})$} & & & \\
\cline { 2 - 6 } & $\lambda$ & $2 \lambda$ & $5 \lambda$ & $10 \lambda$ & $20 \lambda$ & $50 \lambda$ \\
\hline Stainless-steel pipe & 11.76 & 23.52 & 58.82 & 117.64 & 235.29 & 588.23 \\
Ductile pipe & 10.52 & & 52.63 & 105.26 & 210.52 & 526.31 \\
\hline
\end{tabular}



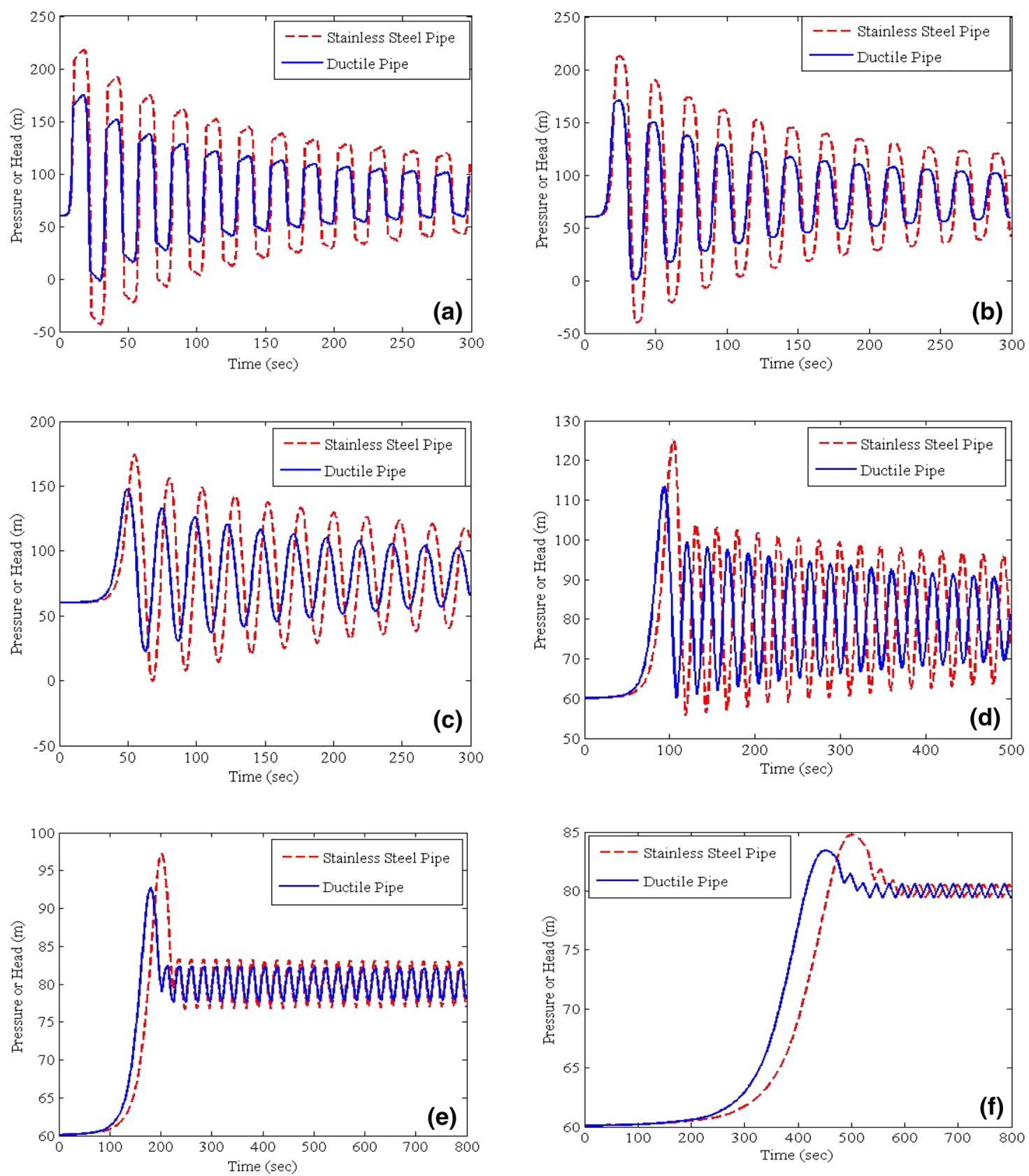

Fig. 4 Transient pressure fluctuation in linear valve closure scheme. a $t=2 L / C^{\prime}$. b $t=4 L / C^{\prime}$. c $t=10 L / C^{\prime}$. d $t=20 L / C^{\prime}$. e $t=40 L / C^{\prime}$.f $t=100 L / C^{\prime}$

the valve opening area were fixed to be $100,40,30$ and 0 . The valve closure time periods and the corresponding valve opening percentages are given in Table 3. In order to comprehend the influence of the closure time on the transient pressure, the time intervals for each step were chosen to be different in each operation. The maximum and minimum pressure heads were recorded to be $215.92 \mathrm{~m}$ and $-41.95 \mathrm{~m}$ for the closure time of 
Table 3 Stepwise valve closure times and valve openings

\begin{tabular}{|c|c|c|c|}
\hline $\begin{array}{l}\text { Valve closure } \\
\text { time }\end{array}$ & $\begin{array}{l}\text { Valve open- } \\
\text { ing (\%) }\end{array}$ & $\begin{array}{l}\text { Time }(\mathrm{s}) \\
\text { Stainless-steel pipe }\end{array}$ & $\begin{array}{l}\text { Time (s) } \\
\text { Ductile pipe }\end{array}$ \\
\hline \multirow[t]{4}{*}{$\lambda$} & 100 & 0 & 0 \\
\hline & 40 & 5.88 & 5.26 \\
\hline & 30 & 8.23 & 7.36 \\
\hline & 0 & 11.76 & 10.52 \\
\hline \multirow[t]{4}{*}{$2 \lambda$} & 100 & 0 & 0 \\
\hline & 40 & 11.76 & 10.52 \\
\hline & 30 & 17.64 & 15.78 \\
\hline & 0 & 23.52 & 21.05 \\
\hline \multirow[t]{4}{*}{$5 \lambda$} & 100 & 0 & 0 \\
\hline & 40 & 23.52 & 21.05 \\
\hline & 30 & 35.29 & 31.57 \\
\hline & 0 & 58.81 & 52.63 \\
\hline \multirow[t]{4}{*}{$10 \lambda$} & 100 & 0 & 0 \\
\hline & 40 & 47.05 & 42.10 \\
\hline & 30 & 70.58 & 63.15 \\
\hline & 0 & 117.64 & 105.26 \\
\hline \multirow[t]{4}{*}{$20 \lambda$} & 100 & 0 & 0 \\
\hline & 40 & 117.64 & 105.26 \\
\hline & 30 & 164.70 & 147.36 \\
\hline & 0 & 235.29 & 210.52 \\
\hline \multirow[t]{4}{*}{$50 \lambda$} & 100 & 0 & 0 \\
\hline & 40 & 235.29 & 210.52 \\
\hline & 30 & 294.11 & 263.16 \\
\hline & 0 & 588.23 & 526.31 \\
\hline
\end{tabular}

$\lambda \mathrm{s}$, and they were $82.36 \mathrm{~m}$ and $60.05 \mathrm{~m}$ for $50 \lambda$ seconds, in stainless-steel pipe, whereas, in the ductile pipe, the maximum and the minimum pressure heads were calculated to be $172 \mathrm{~m}$ and $0.04 \mathrm{~m}$ for $\lambda \mathrm{s}$ and $81.70 \mathrm{~m}$ and $60.02 \mathrm{~m}$ for $50 \lambda$ seconds closure time. The transient pressure fluctuations in the ductile and stainless-steel pipes caused by the stepwise valve closure scheme at different time intervals are shown in Fig. 5. The magnitude of the extreme transient pressure heads was found to be decreasing in the stepwise valve closure operation compared to the linear closure, for the same pipe and closing time periods. A weak line packing was noticed to develop at the crest of the maximum transient pressure line for $\lambda$ closure time, for both pipes. However, for $2 \lambda$ and higher closure time periods, the line packing was not perceived. In the stepwise closure schemes, alike the linear closure schemes, the value of the extreme transient pressures was noted to be decreasing with the increase in the closure time.

\subsection{Extreme transient pressures}

The maximum and minimum transient pressure values recorded due to sudden, linear and stepwise valve closure schemes for different closing times in stainless-steel and ductile pipes are detailed in Table 4 and Fig. 6. As it is perceived from the figure and the table, the absolute value of the maximum and minimum hydraulic transient pressures decreases with the increase in the valve closure time. Moreover, the effect of the pipe material on the hydraulic transients was clearly noted. Under the same hydraulic conditions and the same valve closure time, the maximum value of transient pressure noted in the ductile pipe tends to be less than that generated in the stainless-steel pipe due to the influence of higher friction factor and the modulus of elasticity of the ductile pipe. In order to comprehend the effects of both valve opening percentage and the duration of a closing step, the stepwise valve closure scheme was performed with two scenarios; (1) fixed valve opening percentage with varying closing step duration and (2) fixed closing step duration with different valve opening percentages.

\subsection{Stepwise valve closure with fixed valve opening percentage}

The butterfly valve positioned at the end of the pipeline was closed in three fixed percentage opening steps with varied closure times (Table 5). In the first step, $60 \%$ of the full open valve was closed, then $10 \%$ and in the end the remaining $30 \%$. Although the total closure time was set to be $5 \lambda$, each step was performed in different time intervals, leading to six closing scenarios. In order to determine the influence of stepwise closure on the hydraulic transients, different time step intervals were selected. The maximum transient pressure values were noted to vary from 193.88 to $125.12 \mathrm{~m}$ and 159.07 to $113.38 \mathrm{~m}$ for stainless-steel and ductile pipes, respectively. Furthermore, the magnitude of the transient pressures was found to be decreasing by closing the valve fast at the first step, in a period which is equal to one-fifth of the total closure time, in which $60 \%$ of the valve opening area was closed $[25,37]$. Scenario $A 1$ seems to the optimum solution in terms of the extreme (maximum and minimum) transient pressure values, among the cases considered here. The magnitude of transient pressure in both stainless-steel and ductile pipes is given in Table 6. 

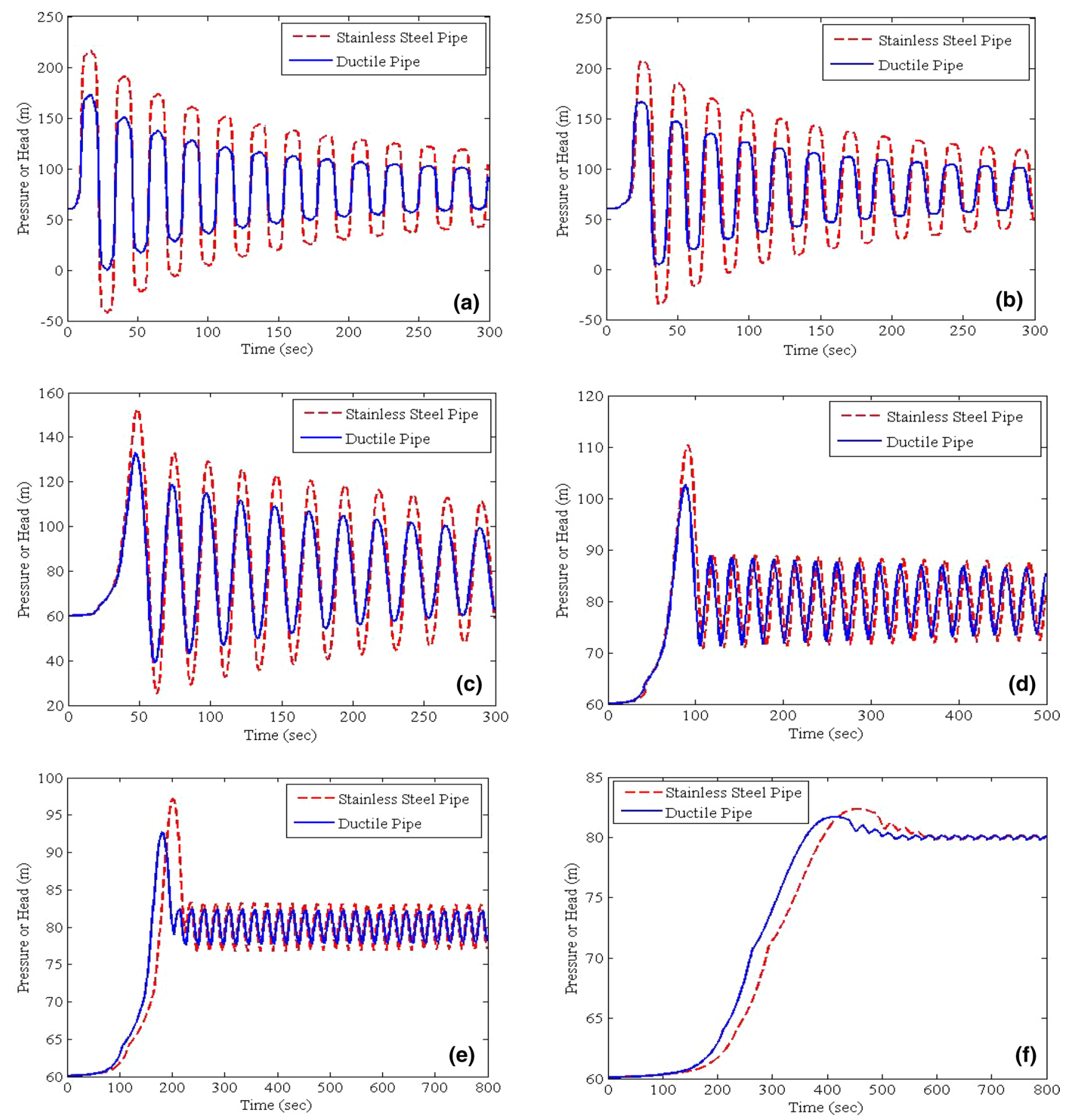

Fig. 5 Pressure fluctuations in stepwise valve closure for different closure times. a $t=2 L / C^{\prime}$. b $t=4 L / C^{\prime}$. c $t=10 L / C^{\prime}$. d $t=20 L / C^{\prime}$. e $t=40 L / C^{\prime}$. f $t=100 \mathrm{~L} / \mathrm{C}^{\prime}$ 
Table 4 Maximum and minimum transient pressures with different closure times

\begin{tabular}{|c|c|c|c|c|c|c|c|c|}
\hline \multirow[t]{2}{*}{ Closure operation } & \multicolumn{2}{|c|}{ Closing time } & \multicolumn{2}{|c|}{ Stainless-steel pipe } & \multicolumn{2}{|c|}{ Closing time } & \multicolumn{2}{|c|}{ Ductile pipe } \\
\hline & $\lambda$ & $s$ & $\begin{array}{l}\text { Maxi- } \\
\text { mum } \\
\text { pressure }\end{array}$ & Minimum pressure & $\lambda$ & $s$ & $\begin{array}{l}\text { Maxi- } \\
\text { mum } \\
\text { pressure }\end{array}$ & $\begin{array}{l}\text { Minimum } \\
\text { pressure }\end{array}$ \\
\hline \multirow[t]{3}{*}{ Sudden } & 0 & 0 & 223.93 & -48.33 & 0 & 0 & 180.03 & -5.77 \\
\hline & $\lambda$ & 11.76 & 217.62 & -43.64 & $\lambda$ & 10.52 & 174.61 & -1.70 \\
\hline & $2 \lambda$ & 23.52 & 212.63 & -39.96 & $2 \lambda$ & 21.05 & 170.55 & 1.04 \\
\hline \multirow[t]{4}{*}{ Linear } & $5 \lambda$ & 58.82 & 174.06 & -0.85 & $5 \lambda$ & 52.63 & 147.01 & -0.85 \\
\hline & $10 \lambda$ & 117.64 & 125.05 & 55.63 & $10 \lambda$ & 105.26 & 113.35 & 55.63 \\
\hline & $20 \lambda$ & 235.29 & 97.20 & 60.05 & $20 \lambda$ & 210.52 & 92.66 & 60.02 \\
\hline & $50 \lambda$ & 588.23 & 84.77 & 60.05 & $50 \lambda$ & 526.31 & 83.43 & 60.02 \\
\hline \multirow[t]{6}{*}{ Stepwise } & $\lambda$ & 11.76 & 215.92 & -41.95 & $\lambda$ & 10.52 & 172.58 & 0.04 \\
\hline & $2 \lambda$ & 23.52 & 206.97 & -34.98 & $2 \lambda$ & 21.05 & 166.20 & 4.76 \\
\hline & $5 \lambda$ & 58.82 & 152.71 & 25.12 & $5 \lambda$ & 52.63 & 132.94 & 38.94 \\
\hline & $10 \lambda$ & 117.64 & 110.36 & 60.05 & $10 \lambda$ & 105.26 & 102.51 & 60.02 \\
\hline & $20 \lambda$ & 235.29 & 97.18 & 60.05 & $20 \lambda$ & 210.52 & 92.68 & 60.02 \\
\hline & $50 \lambda$ & 588.23 & 82.36 & 60.05 & $50 \lambda$ & 526.31 & 81.70 & 60.02 \\
\hline
\end{tabular}

(a)

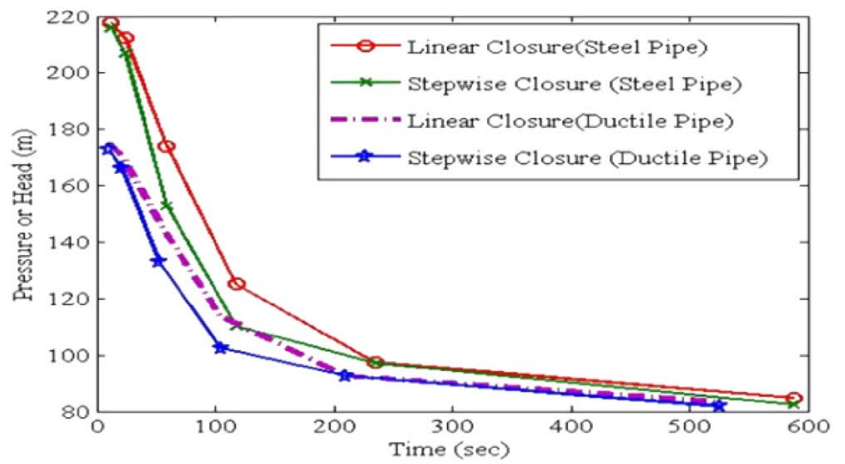

(b)

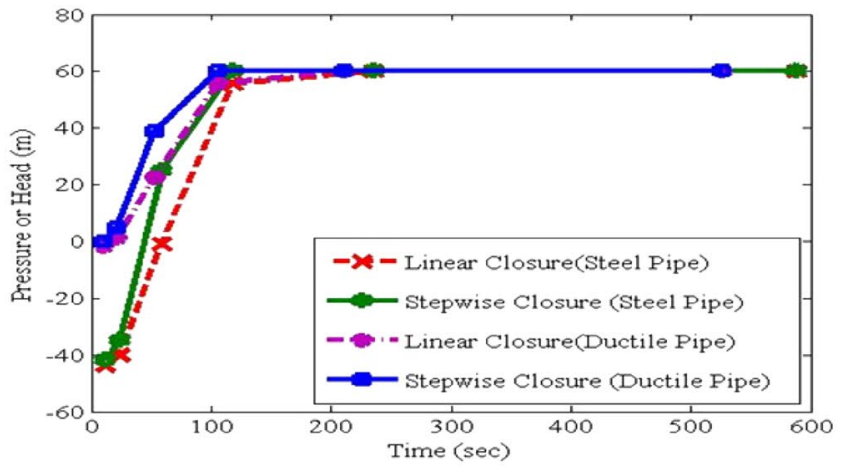

Fig. 6 Transient pressures at different closure times. a Maximum. b Minimum

\subsection{Stepwise valve closure with fixed closing step duration}

In order to perceive the influence of valve opening percentage in a single closure step on the hydraulic transients, each closing step was performed with a fixed time period and different opening percentages, generating six closing scenarios, while the total closure time was set to be $5 \lambda$ (Table 7). The variation of the maximum hydraulic transient pressure values was witnessed to be from
213.96-186.47 $\mathrm{m}$ and $171.70-157.09 \mathrm{~m}$ for stainless-steel and ductile pipes, respectively. The transient pressure values were perceived to be decreasing by closing $60 \%$ of the valve opening area in the first step, then closing $30 \%$ and $10 \%$ of it in the second and third steps, respectively (Scenario B2 in Table 8). The extreme transient pressure values are tabulated in Table 8. Figure 7 illustrates the maximum and minimum transient pressures obtained from all stepwise valve closure scenarios. Scenario A1 (Table 5) was 
Table 5 Stepwise valve closure with fixed opening percentages

\begin{tabular}{|c|c|c|c|c|}
\hline \multirow[t]{2}{*}{ Closure time } & \multirow{2}{*}{$\begin{array}{l}\text { Closing } \\
\text { sce- } \\
\text { narios }\end{array}$} & \multirow{2}{*}{$\begin{array}{l}\text { Valve } \\
\text { opening } \\
(\%)\end{array}$} & $\begin{array}{l}\text { Closing time } \\
\text { (s) }\end{array}$ & Closing time (s) \\
\hline & & & $\begin{array}{l}\text { Stainless-steel } \\
\text { pipe }\end{array}$ & Ductile pipe \\
\hline \multirow[t]{4}{*}{$5 \lambda$} & \multirow[t]{4}{*}{$A 1$} & 100 & 0 & 0 \\
\hline & & 40 & 11.76 & 10.52 \\
\hline & & 31 & 23.52 & 21.05 \\
\hline & & 0 & 58.82 & 52.63 \\
\hline \multirow[t]{4}{*}{$5 \lambda$} & \multirow[t]{4}{*}{$A 2$} & 100 & 0 & 0 \\
\hline & & 40 & 11.76 & 10.52 \\
\hline & & 30 & 47.05 & 42.10 \\
\hline & & 0 & 58.82 & 52.63 \\
\hline \multirow[t]{4}{*}{$5 \lambda$} & \multirow[t]{4}{*}{$A 3$} & 100 & 0 & 0 \\
\hline & & 40 & 23.52 & 21.05 \\
\hline & & 30 & 47.05 & 42.10 \\
\hline & & 0 & 58.82 & 52.63 \\
\hline \multirow[t]{4}{*}{$5 \lambda$} & \multirow[t]{4}{*}{$A 4$} & 100 & 0 & 0 \\
\hline & & 40 & 47.05 & 42.10 \\
\hline & & 30 & 70.58 & 63.15 \\
\hline & & 0 & 58.82 & 52.63 \\
\hline \multirow[t]{4}{*}{$5 \lambda$} & \multirow[t]{4}{*}{ A5 } & 100 & 0 & 0 \\
\hline & & 40 & 11.76 & 10.52 \\
\hline & & 30 & 35.29 & 31.57 \\
\hline & & 0 & 58.82 & 52.63 \\
\hline \multirow[t]{4}{*}{$5 \lambda$} & \multirow[t]{4}{*}{$A 6$} & 100 & 0 & 0 \\
\hline & & 40 & 35.29 & 31.57 \\
\hline & & 30 & 47.05 & 42.21 \\
\hline & & 0 & 58.82 & 52.63 \\
\hline
\end{tabular}

found to be producing the lowest value of extreme transient pressures.

\section{Conclusions}

In this study, the hydraulic pressure transients in a simple pipeline, connecting to two reservoirs and a valve set at its downstream, were examined. The pressure transients were analysed under sudden, linear and stepwise valve closure
Table 7 Stepwise valve closure with fixed time steps

\begin{tabular}{|c|c|c|c|c|}
\hline $\begin{array}{l}\text { Valve } \\
\text { closure } \\
\text { time }\end{array}$ & Scenarios & $\begin{array}{l}\text { Valve } \\
\text { opening } \\
(\%)\end{array}$ & $\begin{array}{l}\text { Time }(\mathrm{s}) \\
\text { Stainless-steel pipe }\end{array}$ & $\begin{array}{l}\text { Time (s) } \\
\text { Ductile pipe }\end{array}$ \\
\hline \multirow[t]{4}{*}{$5 \lambda$} & B1 & 100 & 0 & 0 \\
\hline & & 40 & 35.29 & 31.57 \\
\hline & & 30 & 47.05 & 42.21 \\
\hline & & 0 & 58.82 & 52.63 \\
\hline \multirow[t]{4}{*}{$5 \lambda$} & B2 & 100 & 0 & 0 \\
\hline & & 40 & 35.29 & 31.57 \\
\hline & & 10 & 47.05 & 42.21 \\
\hline & & 0 & 58.82 & 52.63 \\
\hline \multirow[t]{4}{*}{$5 \lambda$} & B3 & 100 & 0 & 0 \\
\hline & & 70 & 35.29 & 31.57 \\
\hline & & 10 & 47.05 & 42.21 \\
\hline & & 0 & 58.82 & 52.63 \\
\hline \multirow[t]{4}{*}{$5 \lambda$} & B4 & 100 & 0 & 0 \\
\hline & & 70 & 35.29 & 31.57 \\
\hline & & 60 & 47.05 & 42.21 \\
\hline & & 0 & 58.82 & 52.63 \\
\hline \multirow[t]{4}{*}{$5 \lambda$} & B5 & 100 & 0 & 0 \\
\hline & & 90 & 35.29 & 31.57 \\
\hline & & 60 & 47.05 & 42.21 \\
\hline & & 0 & 58.82 & 52.63 \\
\hline \multirow[t]{4}{*}{$5 \lambda$} & B6 & 100 & 0 & 0 \\
\hline & & 90 & 35.29 & 31.57 \\
\hline & & 30 & 47.05 & 42.21 \\
\hline & & 0 & 58.82 & 52.63 \\
\hline
\end{tabular}

schemes. Two types of pipes were used in the investigations, namely a stainless-steel and a ductile pipe. The maximum pressure transient values generated in sudden valve closure scheme were noted to be higher than that of linear and stepwise valve closure schemes. Both in linear and in stepwise valve closure, it was perceived that as the closure time period increases, the value of the maximum pressure transient decreases. Stepwise valve closure was found to produce less hydraulic transient than linear valve closure scheme. Also, it was found that in the case of stepwise valve closure, transients can be reduced significantly by
Table 6 Maximum and minimum transient pressures at different time steps

\begin{tabular}{|c|c|c|c|c|c|c|c|c|}
\hline \multirow[t]{2}{*}{ Scenarios } & \multicolumn{2}{|c|}{ Time } & \multicolumn{2}{|c|}{ Stainless-steel pipe } & \multicolumn{2}{|c|}{ Time } & \multicolumn{2}{|l|}{ Ductile pipe } \\
\hline & $\lambda$ & $s$ & Max. pressure & Min. pressure & $\lambda$ & $s$ & Max. pressure & Min. pressure \\
\hline$A 1$ & $5 \lambda$ & 58.82 & 125.12 & 55.64 & $5 \lambda$ & 52.63 & 113.38 & 60.02 \\
\hline$A 2$ & $5 \lambda$ & 58.82 & 188.92 & -25.27 & $5 \lambda$ & 52.63 & 154.50 & 12.9 \\
\hline$A 3$ & $5 \lambda$ & 58.82 & 191.20 & -22.84 & $5 \lambda$ & 52.63 & 156.20 & 11.71 \\
\hline$A 4$ & $5 \lambda$ & 58.82 & 150.86 & 26.10 & $5 \lambda$ & 52.63 & 132 & 39.33 \\
\hline$A 5$ & $5 \lambda$ & 58.82 & 152.65 & 25.18 & $5 \lambda$ & 52.63 & 156 & 38.94 \\
\hline A6 & $5 \lambda$ & 58.82 & 193.88 & -25.27 & $5 \lambda$ & 52.63 & 159.07 & 9.25 \\
\hline
\end{tabular}


Table 8 Maximum and minimum transient pressures at different steps of valve openings

\begin{tabular}{|c|c|c|c|c|c|c|c|c|}
\hline \multirow[t]{2}{*}{ Scenarios } & \multicolumn{2}{|c|}{ Time } & \multicolumn{2}{|c|}{ Stainless-steel pipe } & \multicolumn{2}{|c|}{ Time } & \multicolumn{2}{|l|}{ Ductile pipe } \\
\hline & $\lambda$ & $s$ & Max. pressure & Min. pressure & $\lambda$ & $s$ & Max. pressure & Min. pressure \\
\hline B1 & $5 \lambda$ & 58.82 & 193.88 & -25.27 & $5 \lambda$ & 52.63 & 157.09 & 9.25 \\
\hline B2 & $5 \lambda$ & 58.82 & 186.47 & -0.36 & $5 \lambda$ & 52.63 & 157.07 & 15.96 \\
\hline B3 & $5 \lambda$ & 58.82 & 205.30 & -28.92 & $5 \lambda$ & 52.63 & 168.98 & 3.61 \\
\hline B4 & $5 \lambda$ & 58.82 & 213.70 & -40.81 & $5 \lambda$ & 52.63 & 171.55 & 0.32 \\
\hline B5 & $5 \lambda$ & 58.82 & 213.96 & -41.03 & $5 \lambda$ & 52.63 & 171.70 & 0.21 \\
\hline B6 & $5 \lambda$ & 58.82 & 203.73 & -32.13 & $5 \lambda$ & 52.63 & 169.37 & 0.85 \\
\hline
\end{tabular}

(a)

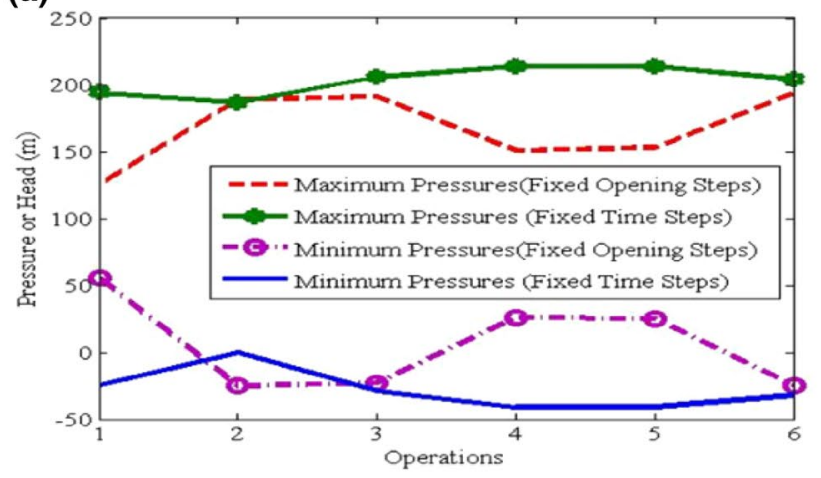

(b)

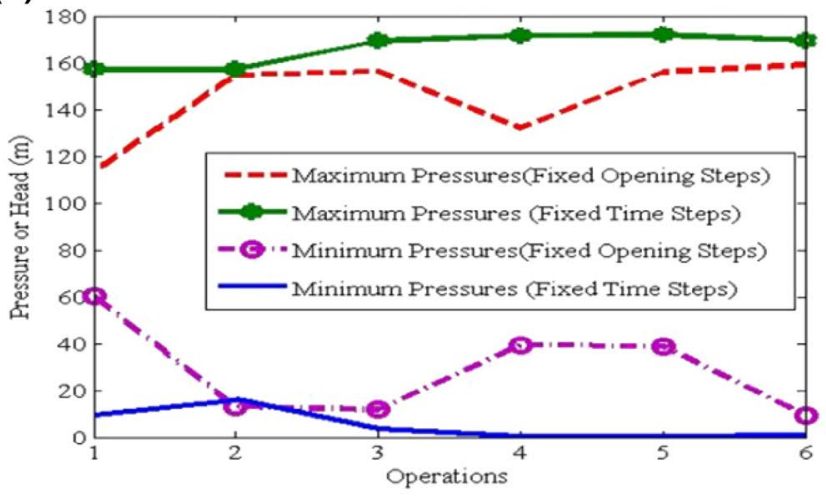

Fig. 7 Extreme transient pressures due to variable valve opening percentage and time steps in a stainless-steel pipe; $\mathbf{b}$ ductile pipe

closing the valve rapidly at the beginning then slowing down to the end. The influence of the type of the pipe was clearly noted in all three sets of the valve closure schemes. The values of the pressure transients detected in the stainless-steel pipe were observed to be higher than those of ductile pipe. Under the same hydraulic conditions, the maximum transient pressure head observed for the stainless-steel pipe was $223.93 \mathrm{~m}$, while it was $180.03 \mathrm{~m}$ for the ductile pipe, which are within the pre-defined limits of the maximum allowable pressure head.

\section{Compliance with ethical standards}

Conflict of interest The authors declare that they have no conflict of interest.

Human and animals rights This article does not contain any studies with human participants or animals performed by any of the authors. The manuscript does not contain clinical studies or patient data.

\section{References}

1. Ghidaoui MS, Zhao M, Mclnnis DA, Axworthy DH (2005) A review of water hammer theory and practice. Appl Mech Rev 58(1):49-76

2. Sirvole K (2007) Transient analysis in piping networks. MSc thesis, Blacksborg, Virginia, Virginia Polytechnic Institute and State University

3. Boulos PF, Karney BW, Wood DJ, Lingireddy S (2005) Hydraulic transient guidelines for protecting water distribution systems. J Am Water Works Assoc 97(5):111-124

4. Bergant A, Simpson AR, Tijsseling AS (2004) Water hammer with column separation: a review of research in the twentieth century. Centre for Analysis Scientific Computing and Applications, Eindhoven University of Technology, Report no: 0434

5. Wood DJ (2005) Water hammer analysis: essential and easy (and efficient). J Environ Eng ASCE 131(8):1123-1131. https:// doi.org/10.1061/(ASCE)0733-9372

6. Provenzano PG, Baroni F, Aguerre RJ (2011) The closing function in the water hammer modeling. Latin Am Appl Res 41(1):43-47

7. Djebedjian B, Mohamed MS, Mondy AG, Rayan MA (2009) Cost optimization of water distribution systems subjected to water hammer. In: Proceedings of 13th international water technology conference (IWTC13), Hurghada, Egypt, pp 12-15 
8. Abuiziah I, Oulhaj A, Sebari K, Abassi Saber A, Ouazar D, Shakameh N (2013) Modeling and controlling flow transient in pipeline systems: applied for reservoir and pump systems combined with simple surge tank. Rev Maroc Sci Agron Vét 1(3):12-18

9. Chaudhry MH (2014) Applied hydraulic transients, 3rd edn. Springer, New York

10. Weston EB (1885) Description of some experiments made on the Providence, R.I., water-works, to ascertain the force of water ram in pipes. Trans Am Soc Civ Eng 14:238-246

11. Carpenter RC (1894) Some experiments on the effect of water hammer. Eng Rec 30:173-175

12. Carpenter RC, Barraclough SH (1894) Experiments on the effect of water hammer. Trans ASME 15:510-535

13. Frizell JP (1898) Pressures resulting from changes of velocity of water in pipes. Trans Am Soc Civ Eng 39(1):1-7

14. Joukowsky NE (1898) Memoirs of the imperial academy society of St. Petersburg. Proc Am Water Works Assoc 24:341-424

15. Joukowsky N (1900) Über den hydraulischen stoss in wasserleitungsrohren, St. Petersburg

16. Allievi $L$ (1903) Teoria generale del moto perturbato dell'acqua nei tubi in pressione (colpo d'ariete) memoria dell'ing, Roma. Unione Coop 17(5):285-325

17. Rich GR (1951) Hydraulic transients, 1st edn. McGraw-Hill, New York

18. Parmakian J (1955) Water hammer analysis. Dover Publications, New York

19. Wylie EB, Streeter VL (1978) Fluid transients. McGraw-Hill, New York

20. Sharp BB (1981) Water hammer, problems and solutions. Edward Arnold Publishers Ltd, London

21. Almeida $A B$, Koelle $E$ (1992) Fluid transients in pipe networks. Elsevier Applied Science, London

22. Karney BW, Ruus E (1985) Charts for water hammer in pipelines resulting from valve closure from full opening only. Can J Civ Eng 12(2):241-264
23. Elansary AS, Contractor DN (1994) Valve closure: method for controlling transients. J Press Vessel Technol 116(4):437-442

24. Sharp BB, Sharp DB (1995) Water hammer: practical solutions. Butterworth-Heinemann, Oxford

25. Yu JY, Wu ZY, Yuan YX, Zhao M, Wu CG (2010) Optimal valve closure for long-distance water transmission. Sustain Environ Res 20(5):287-291

26. Streeter VL, Lai C (1962) Water hammer analysis including fluid friction. J Hydraul Div ASCE 88(3):79-112

27. Wichowski R (1991) Comparative analysis of water-hammer calculation by the approximate and the complete methods of characteristics. Period Polytech Civ Eng 35(1-2):107-125

28. Wylie EB, Streeter VL, Suo L (1993) Fluid transients in systems. Prentice Hall, Upper Saddle River

29. Streeter VL (1972) Unsteady flow calculations by numerical methods. J Basic Eng 94(2):457-465

30. Watters GZ (1979) Modern analysis and control of unsteady flow in pipelines. Ann Arbor Science Publishers, Ann Arbor

31. Safwat HH (1972) Transients in cooling water systems of thermal power plants. PhD Thesis, TU Delft, Delft University of Technology

32. Larock BE, Jeppson RW, Watters GZ (1999) Hydraulics of pipeline system. CRC Press, Boca Raton

33. Bansal, R.K., 2005, A textbook of fluid mechanics, Firewall Media

34. Chen WF, Liew JR (eds) (2002) The civil engineering handbook. CRC Press, Boca Raton

35. Tullis JP (1989) Hydraulics of pipelines: pumps, valves, cavitation, transients. Wiley, New York

36. Gudmundsson JS, Celius HK (1999) Gas-liquid metering using pressure-pulse technology. In: Annual technical conference and exhibition, Houston, Texas

37. Vilberg IK (2010) Airbag for piping systems. MSc thesis, Norwegian University of Science and Technology

Publisher's Note Springer Nature remains neutral with regard to jurisdictional claims in published maps and institutional affiliations. 